\title{
Research on Intelligent Logistics Information System and Its Economic Evaluation
}

\author{
Meiyan Li
}

Xi'an International University, Shaanxi, Xi'an, China, 710077

Keywords: Intelligent Logistics Information System; Evaluation Index; Economic Evaluation

\begin{abstract}
Modern logistics has become the key to supporting Chinese entire logistics industry and express delivery industry. Compared with the traditional logistics, modern logistics using intelligent technology to achieve further enhance and cross. As an important foundation of modern logistics in our country, intelligent logistics has a positive significance to promote the development of Chinese logistics. Based on the analysis of the key technology of intelligent logistics information system, this paper analyzes the existing problems in the intelligent logistics information system from the perspective of economic evaluation, and finally finds out the measures that can solve the economic evaluation of the intelligent logistics information system.
\end{abstract}

\section{Introduction}

Chinese economic development, the transformation of economic structure and so on factors such as the development of Chinese wisdom logistics information system provides a driving force. Information and intelligence has become a business in the fierce market to achieve survival and access to development opportunities [1]. Information and intelligence has penetrated into every aspect of Chinese logistics enterprises, the most important feature of modern logistics. A company's own logistics information and intelligent level to a large extent determine the future development of an enterprise. Intelligent logistics information system has been more and more logistics enterprises, how to understand the economic benefits and how to evaluate, which is intelligent logistics information system is critical.

\section{Key Technology Analysis of Intelligent Logistics Information System}

Automatic identification technology, the technology is mainly used for storage, transportation, packaging and distribution and other sectors. Automatic identification technology includes bar code technology, radio frequency identification technology, biometric technology and magnetic stripe technology [2].

Mobile communication technology, the key to the technology is that if the company can timely understand the information and the sensitivity of the information, you can in the entire market competition to obtain a certain initiative.

Intelligent transportation technology, intelligent transportation technology includes mobile information technology, vehicle positioning technology and vehicle identification technology. Which vehicle positioning technology to understand the real-time status of transport vehicles, scheduling vehicles, optimize the transport path has a significant effect.

Data warehousing and data mining technology, due to the arrival of large data age enterprises want to obtain valuable information from the massive data and we must use the relevant data 
processing technology, which implied the actual meaning of data mining, for the development of enterprises to provide decision-making.

\section{Problems in the Economic Evaluation of Intelligent Logistics Information System}

The Strategic Awareness Is Not Strong. Logistics enterprises to achieve the development of information technology needs to step by step to build up, if there is no information strategy to guide a very easy to develop in the process of deviation. From this point can be found in the information strategy to a certain extent affect the wisdom of the logistics information system economy, and thus affect the economic evaluation methods. The wisdom of the enterprise logistics information system in the development, construction, operation process needs information technology strategy guidance, but many enterprises on the wisdom of the logistics information system understanding is not deep enough, the lack of strategic vision, and did not form a long-term strategic planning.

The Overall Level of Intelligent Logistics Information System Is Low. At present, Chinese enterprises in the process of economic evaluation of the wisdom of the logistics information system, which are the system development of the target forward-looking evaluation, the practical operation of the system evaluation, system performance portability evaluation of the degree of attention is not enough, It is also difficult to realize the economic evaluation of intelligent logistics information system. As the intelligent logistics information system in the process of development and construction covers a variety of factors in the community as well as economic, political, etc., want to wisdom of the logistics information system to make an objective and comprehensive evaluation, more difficult.

The Standard System of Logistics Information Is Not Perfect. Because there is not a scientific and reasonable standards, leading to want to evaluate the wisdom of the logistics information system economy there is a certain degree of difficulty. Reasonable standards are not just industry standards, but also information standards. The information standard for logistics is different from other industry standards. It is not only an effective way to standardize the whole logistics behavior and evaluate the intelligent logistics information system, but also to promote the development of intelligent logistics information system has a positive significance. As a result of the formation of a reasonable system, leading to the intelligent logistics information system between enterprises to achieve the sharing and communication of resources is very difficult, not only affect the wisdom of the logistics information system application and promotion, but also restricts the development of Chinese enterprises.

\section{Achieve the Establishment of Intelligent Logistics Information System Economic Evaluation Index}

Construction Principles. (1) The establishment of intelligent logistics information system economic index system, the first need to consider is the indicators in the establishment of the process are measurable. Only on this basis to ensure that the indicators are objective and practical, to ensure the evaluation of the objectivity of the results [3]. In addition, only the practical principle can be demonstrated in the information system to the economic evaluation of a wide range of applications and promotion.

(2) The economic evaluation of the intelligent logistics information system, which not only contains the economic indicators, but also includes the system development, system operation and other aspects of the indicators, so the need for qualitative analysis and quantitative analysis of the principle of wisdom Optimization and Perfection of Logistics Information System. 
The Establishment of Economic Evaluation Index System. The establishment of intelligent logistics information system economic evaluation index system aims to help enterprises to achieve information security and access to good economic benefits. This paper analyzes the relevant indexes of economic evaluation of intelligent logistics information system, and finds out that the economic index system of intelligent logistics information system mainly includes system development, system construction, system operation, system performance, system technology and so on. The system development also includes the goal of forward-looking, development efficiency, development applicability, security, system scalability, system reliability. System construction includes target implementation, management science, resource utilization, construction and other norms. System operation includes system practicality, system timeliness, system sharing, ease of operation, and user friendliness. System performance includes system stability, system reliability, system maintainability, system scalability, and the like. System technology includes system efficiency, technical flexibility, data processing and management capabilities. Economic benefits include cost-benefit ratio, order processing speed, cargo loss rate and so on.

Achieve the Optimization of Economic Evaluation Index System. In the above mentioned indicators, not all of the indicators as part of the system, the priority resources to analyze the important indicators, so optimization is necessary. Intelligent logistics information system development first need to consider is the development of the target, the development of efficiency, the development of the applicability and the value of development [4].

\section{Effective Measures Analysis to Improve the Economy of Intelligent Logistics Information System}

Establish Intelligent Logistics Information Development Strategy. Enterprises want to achieve the wisdom of logistics information system of good application and development, you need to have a strategic awareness, develop a scientific development strategy. Through the logistics enterprises to establish a smart logistics information system, through the control of the entire business activities and management, we can achieve effective internal resource sharing, and promote economic interests to maximize. Enterprises in the development and application of intelligent logistics information system in the process, you can learn abroad and domestic has successfully applied the wisdom of logistics information system, the successful experience of enterprises, and then according to their own business situation to develop a reasonable development strategy to achieve scientific management.

Strengthen the Intelligent Logistics Information Standard System. The construction of the intelligent logistics information standard system involves all the links in the enterprise and even the various stakeholders of the society. Therefore, each party needs to contribute to the establishment of a set of easy and simple standard system. The content of the system should not only include the wisdom of logistics information and logistics technology and other aspects of the standard [5], but also need to improve the logistics information system as the goal of the development and revision of logistics and information technology standards for the wisdom of the logistics information system and its economy Evaluation of the provision of data support. As the whole logistics activities in China gradually complicated and in-depth, in order to better manage the logistics business and to achieve the standardization of daily activities management, the need to introduce the relevant logistics information standards, coordination of the entire logistics management, which requires the community to actively participate in individual To the establishment of logistics information standards to work.

Give Full Play to the System Evaluation Function. The face of intelligent logistics 
information system development and establishment, the first need to do is to the needs of the entire market analysis, to be able to guide the follow-up system development work. Determine the centralized alternative development program, and then compare the analysis of which enterprises can get the most cost-effective program, as a feasibility program for development. In addition, due to the development of intelligent logistics information system, need to have sufficient human, material and financial support, so companies need to do a good job of preparation. Through the economic evaluation of the development process of the intelligent logistics information system, the risk of the development process is effectively avoided, and the whole system operation, performance, economic benefit and social benefit can be improved by adjusting the direction of the system development.

In-Depth Promote the Intelligent Logistics Information Technology Applications. The use of logistics information technology constantly updated and development, many companies did not really achieve the wisdom of the logistics of information technology applications, which largely limits the wisdom of the long-term development of information systems. The enterprise itself needs to enhance the level of information, on the basis of the realization of intelligent logistics information technology applications [6]. Businesses can also seek help from government departments.

Enhance the Use of Intelligent Logistics Information System Value. As the entire wisdom of the logistics information system contains a variety of information technology, which not only requires a variety of talent support and maintenance, but also covers a lot of logistics data and so on [7]. There are many elements that make up the intelligent logistics information system. In order to evaluate the economics of the intelligent logistics information system effectively, it is necessary to analyze each factor and ensure the development of the system in the process of system development, construction and operation. On this basis, it comprehensively enhances the value of intelligent logistics information system.

\section{Conclusion}

Based on the analysis of the key technologies in the intelligent logistics information system, this paper analyzes the problems existing in the economic evaluation of the intelligent logistics information system, and finally analyzes the wisdom of the intelligent logistics information system from the perspective of the construction and the angle of view. Logistics information system analysis, the ultimate goal is to hope for enterprises to build intelligent logistics information system and intelligent logistics information system to provide a reference for economic evaluation.

\section{References}

[1] Wang Chuanlei, Wang Yan.Study on Intelligent Logistics Information System Based on Data Cube [J]. Logistics Technology, 2013, 15: 243-247.

[2] Jin Henggen, Hong Chenglin. Analysis of the Effect of Logistics Information System on Supply Chain Cooperation - Taking Korean Customs as an Example[J]. Logistics Technology, 2011, 11: 207-210.

[3] Luo Lihong. Intelligent logistics is the key to information collection - based on the product coding technology RFID product logistics supply chain management system [J]. China Automatic Identification Technology, 2013, 05: 72-74. 
[4] Zhang Guowu. Large Data and Wisdom Logistics - "Traffic $7+1$ Forum" The thirty-seventh meeting of the document [J]. Transportation Systems Engineering and Information, 2015, 01: 2-10.

[5] YAN Jun-xia, WU Bai-han.Study on Intelligent Logistics Distribution Management Information System Based on ArcSDE [J]. Journal of Handan College, 2015, 02: 125-128.

[6] Tang Jianrong, Xu Yuanyuan, Li Xiaojing. Analysis of Urban Logistics Driving Factors Based on SEM and Its Countermeasures - Taking Jiangsu Province as an Example [J]. East China Economic Management, 2015, 08: 39-46.

[7] Xu Zhenyu, Zhang Shenggui, Xu Yuehua.Study on Competitive Ability of Port Logistics System Based on Fuzzy Information Entropy Theory - Taking Fuzhou Port Intelligent Logistics and Low-carbon Port Construction as an Example [J]. Journal of Applied Functional Analysis, 2014, 02: $129-137$ 